\title{
Uma experiência através de jogos lúdicos no aprendizado do semiárido ${ }^{1}$
}

An experience through ludic games in the semiarid learning

Una experiencia a través de juegos lúdicos en el aprendizado del semiario

\author{
José Falcão Sobrinho
}

Prof. Dr. do Programa de Mestrado Acadêmico em Geografia da Universidade Estadual Vale do Acaraú/UVA. Estágio pós doutoral do Curso de Geografia na UFC. Apoio: falcao.sobral@gmail.com

\section{José Marcelo Soares Oliveira}

Geógrafo. Resultou no trabalho de conclusão de curso em Geografia.

\section{Edson Vicente da Silva}

Prof. Pós doctor do Programa de Pós Graduação em Geografia da Universidade Federal do Ceará/UFC. cacauceara@gmail.com

\section{Cleire Lima da Costa Falcão} Profa. Dra. da Universidade Estadual do Ceará/UECE. cleirefalcao@gmail.com

${ }^{1}$ Projeto de pesquisa desenvolvido com apoio do CNPq (Chamada MCTI/CNPQ/MEC/CAPES No 22/2014).. 


\section{RESUMO}

Através do presente ensaio pretende-se referenciar acerca do tratamento que é dado as práticas educativas que visam uma melhor convivência no ambiente semiárido, a partir de suas características peculiares, associando-se à educação contextualizada. Desta forma, propõe-se inserir os jogos lúdicos, a fim de promover uma melhor assimilação acerca da realidade vivida nesse ambiente. Neste contexto, há de se introduzir sobre a temática vista em conjunto com o ensino de geografia. Daí, adotamos a inserção de oficinas com alunos do Ensino Fundamental Il do colégio Maria do Carmo Andrade, no bairro Pedrinhas, no município de Sobral, Ceará, Brasil. Utilizamos jogos lúdicos para refletir a questão do semiárido. Constatou-se que é válido enfatizar a questão de aplicabilidade de tais alternativas na prática do ensino, ocasionando um envolvimento dos participantes.

Palavras-chave: Educação contextualizada; Semiárido; Ensino de Geografia; Lúdico.

\section{SUMMARY}

The aim of this essay is to refer to the treatment that is given to educational practices that aim at a better coexistence in the semi-arid environment, based on its peculiar characteristics, associating with contextualized education. In this way, it is proposed to insert play games, in order to promote a better assimilation about the reality lived in this environment. In this context, it is necessary to introduce on the theme seen together with the teaching of geography. Hence, we adopted the insertion of workshops with Elementary School II students of the Maria do Carmo Andrade School, in Pedrinhas neighborhood, in the municipality of Sobral, Ceará, Brazil. We play games to reflect the question of the semi-arid. It was verified that it is valid to emphasize the question of applicability of such alternatives in the teaching practice, causing an involvement of the participants.

Key words: Contextualized education; Semi-arid; Geography Teaching; Playful.

\section{RESUMEN}

A través del presente ensayo se pretende referir sobre el tratamiento que se da a las prácticas educativas que apuntan a una mejor convivencia en el ambiente semiárido, a partir de sus características peculiares, asociándose a la educación contextualizada. De esta forma, se propone insertar los juegos lúdicos, a fin de promover una mejor asimilación acerca de la realidad vivida en ese ambiente. En este contexto, hay que introducir sobre la temática vista en conjunto con la enseñanza de geografía. De ahí, adoptamos la inserción de talleres con alumnos de la Enseñanza Fundamental II del colegio Maria do Carmo Andrade, en el barrio Pedrinhas, en el municipio de Sobral, Ceará, Brasil. Utilizamos juegos lúdicos para reflejar la cuestión del semiárido. Se constató que es válido enfatizar la cuestión de la aplicabilidad de tales alternativas en la práctica de la enseñanza, ocasionando una participación de los participantes.

Palabras clave: Educación contextual; Y en el caso de las mujeres. Enseñanza de Geografía; Lúdico. 


\section{INTRODUÇÃO}

O estudo do contexto educacional evidenciado na região semiárida brasileira é preponderante ao passo que nos detalharmos de forma minuciosa e pôr em evidência que a região se trata da área semiárida com o maior contingente populacional (SILVA, 2006), consistindo numa diversidade econômica, social, cultural e natural. Além do mais, trata-se aqui, de uma tentativa de levar um conhecimento acerca da realidade semiárida, no viés de situá-los sobre práticas adequadas no manejo do sistema ambiental da nossa região. Nesse caso, o trabalho visa enfatizar a não dissociação dos espaços rural e urbano que apesar desta relação estar cercada de estereótipos que só ratificam a presença de um sistema educacional, às vezes, desconexo de qualquer prática integradora dos ambientes.

Desta forma, problemas de escassez de alimentos e falta d'água rotineiramente subjulgados ao meio rural, atingem os mais modernos e numerosos centros urbanos. $E$ a educação contextualizada sobre à região Semiárida não poderia ficar fora de qualquer pauta de discussão. Podendo a mesma ser engendrada de forma integrada e interdisciplinar, possibilitando um diálogo intermitente não somente com à Geografia, bem como outras áreas do conhecimento como, Literatura, Biologia, História. Contextualizando numa linguagem geográfica, deve-se ocorrer preocupações com a distribuição no espaço, tempo, causa e examinar possíveis soluções.

O entendimento sobre a realidade semiárida necessita de bases introdutórias a partir das séries iniciais do ensino básico. No entanto, a problemática da má utilização de recursos didáticos ou mesmo a ausência deles em sala de aula prejudica o processo de ensinoaprendizagem, urgindo a necessidade da idealização de metodologias que seduza os alunos. De acordo com os parâmetros curriculares nacionais/PCN's (BRASIL, 1998), no ensino fundamental, a Geografia tem como propósito o ensino da dinâmica estabelecida no cotidiano entre sociedade e natureza e de forma mais ampla quando nos deparamos com as propostas dos PCN's do Ensino Fundamental podemos analisar que a educação escolar tem a possibilidade de fornecer aos alunos uma base para a construção de conhecimento necessário à compreensão da realidade e de forma conjunta com manifestações culturais, sociais e políticas diversas (BRASIL, 1997).

Dentro deste discurso esse trabalho irá propor o encaminhamento sobre o tratamento lúdico de forma conjunta com a produção de saberes do/no Semiárido através do desenvolvimento de novos jogos: Quebra-cabeça e Erros da Convivência, que podem vir a contribuir para entender a dinâmica do ambiente tratado contextualizando no que diz respeito a introdução de produção de saberes acerca de uma realidade.

\section{AS CARACTERÍSTICAS DO SEMIÁRIDO BRASILEIRO}

De acordo com o Ministério do Meio Ambiente, o semiárido brasileiro ocupa uma área de $18,2 \%\left(982.566 \mathrm{Km}^{2}\right)$, em se tratando do território nacional, se fazendo presente em mais de $20 \%$ dos municípios brasileiros (1.133). Ao nos referirmos a questão demográfica, podemos destacar que a região semiárida abrange um contingente populacional de mais de 22 milhões de seres humanos, ainda de acordo com a MMA, o Semiárido permeia cerca de $18 \%$ do território do Estado de Minas Gerais. 
Sobre a caracterização econômica, a realidade é marcada por paradoxos, principalmente na sua estrutura fundiária, pela convivência dialética entre os grandes latifúndios, estes voltados à exportação, e pequenas propriedades as quais ainda se utilizam de práticas de manejo do solo inadequadas como: desmatamento que causam a erosão do solo semiárido, raso e pedregoso. O que evidência a necessidade de uma educação contextualizada, que possa contribuir com a realidade da forma de uso dos solos.

A este respeito Costa Falcão (2009), aborda em relação as práticas conservacionistas do solo, haja visto que a mesma realizou estudos relativos ao manejo dos solos na depressão sertaneja, determinadas práticas preponderam, principalmente em ambientes os quais necessitam de maior cuidado, como no caso do semiárido, em razão dos solos serem pouco profundos, se faz necessário cientificar as perdas e adições. Costa Falcão (2009) cita que:

\begin{abstract}
Em razão do desgaste e do empobrecimento do solo, para melhor conserva-lo e restaurá-lo, recomenda-se 0 uso de práticas conservacionistas, visando especificamente ao controle da erosão, diminuindo o processo erosivo, que se inicia com o impacto das gotas de chuvas sobre o solo, seguido do rebaixamento da camada superficial pelas águas de enxurradas. Estas práticas de recuperação tornamse indispensáveis, pois levam às terras melhores condições de produtividade. Dentre as principais, recomendam-se uniformização do terreno sulcado pela erosão, rotação de culturas, adubação verde e calagem, caso necessário (p. 57)
\end{abstract}

Nesse sentido, ao compor uma base que tenha como eixo a educação temos então, de compor uma base alicerçada em estudos referentes ao manejo correto dos solos como, agroecologia; rotação de culturas; preservação de matas ciliares e dentre outras. É válido ressaltar que não se trata de uma tarefa fácil, em razão de os pequenos agricultores reproduzirem práticas que permeiam gerações de suas famílias, sendo assim, mais uma das problemáticas que se observa sobre o modelo cultural, que necessita ser revitalizado e de responsabilidade que também recai sobre a questão da educação. A pesar do recente crescimento econômico da região, de forma substancial nas áreas de serviços e turismo, o Semiárido e o Nordeste ainda respondem por uma grande parcela de dependência dos programas assistencialistas do governo.

Referente ao Estado do Ceará, o Semiárido compõe 92\% do território e, além do baixo regime pluviométrico os solos encontram-se bastante degradados (SOUZA, 2006). Seguindo o pensamento de Souza (2006) o estado do Ceará ocupa um território de $148.016 \mathrm{Km}^{2}$ entre as coordenadas de $3^{\circ} 46^{\prime} 30^{\prime}$ e $7^{\circ} 52^{\prime} 54^{\prime \prime}$ Latitude Sul e $37^{\circ} 14^{\prime} 54^{\prime \prime}$ e $41^{\circ} 24^{\prime} 55^{\prime \prime}$ Longitude Oeste Gr. Ao observarmos a questão social, podemos destacar a demografia da região como empecilho, visto que se concentra um alto contingente populacional e existe uma desarticulação entre a ausência de políticas de planejamento familiar e favorecimento das elites dominantes.

Em consonância com a caracterização climática, destaca-se a relação dependente, que há entre a hidrologia e clima da região, ocorre má distribuição de chuvas no tempo e espaço, com médias anuais que giram em torno de 268 a $800 \mathrm{~mm}$ de precipitações. Especificando acerca do Vale do Acaraú, Falcão Sobrinho (2007) destacando o Vale do Acaraú, aborda sobre a imprescindibilidade de se ter no clima um suporte na leitura histórica das paisagens de determinada região.

Neste contexto, ainda há preponderância de estudos generalizantes, sem mais detalhamentos no que tange as características das diversas áreas da região. Fato exemplificado através das diferenças de precipitações nas áreas de maciço residual úmido, superfície sertaneja e litoral. No caso, níveis de temperatura, quantidade de dias de isolação, erodibilidade, vegetação e, portanto, onde pouco são levados em consideração em se tratando de estudos mais 
aprofundados. A área analisada está submetida a 3 a 5 meses de chuvas, com mais intensidade em no máximo 3 meses (FALCÃO SOBRINHO, 2007).

Além do mais, Silva (2006) assinala que nos últimos períodos o Semiárido presenciou um aumento significativo na população urbana, fato evidenciado pelo decréscimo do contingente habitante da zona rural. Este fato está diretamente interligado ao declínio da produção algodoeira e demais produções advindas da pecuária e culturas de subsistência.

E para nos detalharmos melhor sobre a região podemos então contextualizar a sua vegetação como sendo em maior representatividade a Caatinga, esta possuindo características xerófilas, dispõem de folhas reduzidas a espinhos para dificultar uma rápida perca de água, em suas espécies. Além disso, a conjuntura de semiaridez se reforça pela presença de solos rasos e pedregosos, cristalinos, retratando na qualidade da água, porque em razão da alta concentração de sais minerais o recurso hídrico torna-se quase que inutilizável (SILVA, 2006). Ab'Saber (2003), com base em estudos de George H. Hargreaves, assinala a presença de quatro ou agrupamentos sub-regionais no interior do semiárido: o semiárido acentuado ou desértico, semiárido rústico ou semiárido típico, semiárido moderado, e subáreas de transição ou faixas subsumidas.

\section{EDUCAÇÃO CONTEXTUALIZADA NO SEMIÁRIDO}

Podemos considerar educação contextualizada como sendo parte integrante de todo um sistema complexo e interdependente que é a sociedade. Partimos então para analisar este acontecimento que vise a educação de maneira horizontal e estabelecimento de diálogos intermitentes. Contextualizar a educação, significa em pormenores, promover debates que dizem respeito a realidade vivida e conhecimentos elaborados a partir de premissas que corroborem para produção de saberes que exaltem os próprios alunos (QUINTELLA BAPTISTA e CAMPOS, 2013).

Ao nos determos sobre educação no Semiárido, entende-se a questão que, mesmo o ensino nas formas tradicionais fora negado ao homem sertanejo e sem argumentos o mesmo teve perpetuado o pensamento, por parte da elite, de pertencer a uma classe rodeada somente de folclores, mitos e superstições. A região estudada exala aspectos culturais e comportamentais bem característicos, um dos exemplos encontramos na literatura de cordel, a qual poderia ser mais bem utilizada pelo sistema educacional governamental.

Além disso, no tocante a importância da escola básica, neste processo, temos que nos reportar até Paulo Freire em "Teologia da Libertação", utilizando-se de objetos do cotidiano da realidade sertaneja (QUINTELLA BAPTISTA e CAMPOS, 2013). Refletindo melhor, visualizamos que educação contextualizada não se restringe apenas às zonas rurais, mas também em qualquer local que exija aprofundamentos sobre realidade, trabalho necessário frente as necessidades, seja de estudantes, agricultores, ou demais setores da sociedade.

\subsection{Do contexto histórico da educação brasileira à prática do professor/pesquisador na geografia escolar do ensino básico}

Os PCN, LDB, PNLD e outros documentos do governo referentes à educação foram elaborados dentro de uma atmosfera econômica que propunha a efetivação do Estado Mínimo, ou seja, a implantação de medidas neoliberais, onde se impõe a necessidade de promover no Estado o menor número de atribuições legais, sendo a educação tratada da mesma maneira de outros setores do país, de forma "eficiente" e maximização de tempo (CACETE, 2013). 
Além do mais, sob indicações do Banco Mundial, o governo brasileiro teve que seguir a adotar medidas centralizadoras quanto à educação, examinando este aspecto, podemos nos atentar sobre a padronização dos currículos. Críticas vieram, principalmente, da Associação dos Geógrafos Brasileiros - AGB, logo questionava-se a centralização e verticalização das decisões do governo, sem a interação e discussões com os maiores interessados no processo educacional, professores e comunidade escolar. Para Cacete (2013) os PCN's encaminharam apenas no viés do livro didático, fazendo destes os atuais protagonistas do sistema educacional.

As leis de Diretrizes e Bases da Educação Nacional - LDB, estabelece, dentro de uma interpretação a qual nós fazemos sobre currículos, podemos determinar que, no seu artigo 26, numa resolução modificada em 2013, através da lei $n^{\circ} 12.796$, diz-se que, há de se considerar uma padronização nacional, com ressalvas no que diz respeito à adequação dos currículos frente as diversidades regionais econômicas, culturais e sociais dos alunos Brasil (1996).

No contexto do ensino Geografia, fez-se traduz através do exercício da docência ou em estágios supervisionados, é a influência direta do que é para ser seguido pelos professores quanto à conteúdos como afirma Pontuschka (1999):

A disciplina escolar geográfica está no jogo dialético entre a realidade da sala de aula
e da escola, entre as transformações históricas da produção geográfica na academia
e as várias ações governamentais representadas hoje pelos guias, propostas
curriculares, parâmetros curriculares nacionais de geografia; avaliações impostas aos
professores, sem mudanças radicais na estrutura da escola e na organização
pedagógica global e pelo embate acirrado entre escola pública e privada. (p. 111)

Sobre isto, temos em debate que, insere, a discussão acerca da necessidade de repensar as práticas de ensino de forma horizontal, projetando relações que corroborem para o diálogo constante entre professor, aluno e conteúdo. A disciplina geográfica até antes de 1960, versava apenas por conteúdos meramente descritivos, passando pelo período histórico que compreende a ditadura o qual supunha a dizimação das disciplinas de Geografia e História conforme Conti (1976, apud Pontuschka, 1999). Por conseguinte, nas décadas de 1980 e 1990 cresceu-se significante as produções sobre o ensino de Geografia com viés na formação de professores.

Soma-se a este fato, a discussão sobre a capacidade de transmissão de saberes, por parte dos professores, logo que tal necessidade passa a ser introduzida a partir de um arcabouço teórico e metodológica bem elaborados como assinala Pontuschka (1999):

O trabalho do professor do ensino fundamental e médio é complexo, pois, além de realizar a leitura do espaço geográfico, ou dos espaços geográficos precisa fazer a leitura da realidade específica de seus alunos e daquilo que eles conhecem sobre o espaço geográfico; compreender de onde se originam seus conhecimentos e suas representações, frutos da vivência, do senso comum. Que conhecimentos podem se traduzir em "não-conhecer" ou falso conhecimento. Só então o professor estará apto a propor problemas desafiadores de caráter geográfico para a ânsia de conhecimento que a criança e o adolescente possuem, mas que, muitas vezes, não têm a oportunidade de externar na escola, em decorrência dos métodos passivos utilizados pelo docente. (p. 133) 
Dimensionando os fatos, o papel do profissional docente enquanto intermediador de conhecimentos está subordinado a uma condição que adentra a sua sensibilidade na promoção de saberes atrelados a realidade vivida por determinada comunidade escolar.

Para abordar melhor sobre o exercício docente, temos então de discutir os processos educacionais numa perspectiva histórica e o aprofundamento acerca da interação entre professor-aluno. No caso, Suertegaray (2004) também ressalta a importância da atuação do profissional docente em estabelecer a pesquisa como sendo também parte de seus atributos. A ideia de formação dos professores não deve caminhar nos moldes da "educação bancária", assim descrita por Paulo Freire, onde se prepondera a concepção da mera exposição de conteúdos "prontos", sem se ter a construção de conhecimentos, visto que este processo deve se configurar a primazia pelo caráter da convivência e integração de valores.

A preocupação com a maneira de ensinar Geografia em sala de aula veio, sobretudo, a partir dos anos 1970, de forma conjunta com a inserção dos Encontros Nacionais de Ensino de Geografia, promovidos pela AGB, Associação dos Geógrafos Brasileiros, antes disso, lecionar a disciplina na escola, caracterizava-se pelo simples fato de descrição do quadro natural do país (CAVALCANTI, 2004. p. 18). Cavalcanti (2004) ainda discorre sobre a importância de refletirmos acerca na nova forma de se ensinar, que nada tem de novo, apenas deve-se levar em consideração a interação entre os fatos humanos e físicos da Geografia em sala de aula. Cavalcanti (2004) demonstra:

\begin{abstract}
(...) Nessa perspectiva, os estudiosos alertam para a necessidade de se considerar o saber e a realidade do aluno como referência para o estudo do espaço geográfico. 0 ensino de Geografia, assim, não se deve pautar pela descrição e enumeração de dados, priorizando apenas aqueles visíveis e observáveis na sua aparência (na maioria das vezes impostos à "memória dos alunos, sem real por parte destes). Ao contrário, o ensino deve propiciar ao aluno a compreensão do espaço geográfico na sua concretude, nas suas contradições. (p. 20)
\end{abstract}

Verifica-se o destaque o qual devemos ter no que tange a propagação de mais reflexões resultantes e em trabalhos divulgados com a preocupação com o conteúdo e a metodologia mais adequada. Não se trata apenas no domínio dos conhecimentos científicos e repassá-los, há de considerarmos se dilogam com a realidade dos educandos.

Dentro deste viés, optamos por adentrar à perspectiva socioconstrutivista, dando ênfase ao trabalho de Cavalcanti (2004), no qual a autora analisa a prática docente alinhada com a teoria construtivista de Vigotsky, nesse processo o professor atua como mediador de conhecimento constituindo numa relação de troca, nesse processo nenhuma das partes envolvidas se caracteriza como sujeito passivo, neste caso, há o constante diálogo entre os conhecimentos de ambos.

\title{
4. MATEERIAL E MÉTODO
}

\subsection{Materiais de apoio didático ao entendimento do semiárido}

Como acabamos de abordar sobre pesquisas no ensino, nada mais justo do que pôr em prática o resultado de inúmeros estudos. Visando elaborar alternativas mais lúdicas e com isso promover melhor assimilação do conteúdo Semiárido, propomos incumbir os jogos dos errose quebra-cabeça da convivência com o Semiárido, estimulando a produção do saber. Para a elaboração dos mesmos, se fez necessário estudos acerca do lúdico na aprendizagem, de acordo Goulart (1983): 
Está ligado a demonstrar valores afetivos, culturais e de lazer. Dentro do contexto alinhamos o pensamento as pesquisas que fomentaram discussões acerca da inserção da Psicologia da Educação quando nos remetemos ao nível que pode ser exigido de cada fase de desenvolvimento humano. Contribuindo ao trabalho destacamos o construtivismo de Piaget e Vigotsky. Neste sentido e relacionando ao desenvolvimento de jogos e outras práticas lúdicas, Costa Falcão (2014) relata:

Torna-se imprescindível e de fundamental importância, o trabalho e a flexibilidade do professor não só de Geografia, mas das demais áreas adotar metodologias e recursos didáticos que possam correlacionar os conteúdos a fim de expandir o raciocínio dos alunos, sistematizar os conhecimentos e despertar o interesse dos mesmos. (p. 179)

Por estes motivos optou-se por desenvolver os materiais observando sobre o tamanho dos desenhos e quantidade de peças do quebra-cabeça. Conforme Piaget (1967) apud Goulart (1983), "o jogo não pode ser visto apenas como divertimento ou brincadeira para desgastar energia, pois ele favorece o desenvolvimento físico, cognitivo, afetivo e moral". Através dele se processa a construção de conhecimento, principalmente nos períodos sensório-motor e préoperatório. Agindo sobre os objetos, as crianças, desde pequenas, estruturam seu espaço e seu tempo, desenvolvendo a noção de casualidade, chegando à representação e, finalmente, à lógica. As crianças ficam mais motivadas para usar a inteligência, pois querem jogar bem, esforçam-se para superar obstáculos tanto cognitivos como emocionais. 
Figura 1. Jogo dos erros da preservação do semiárido
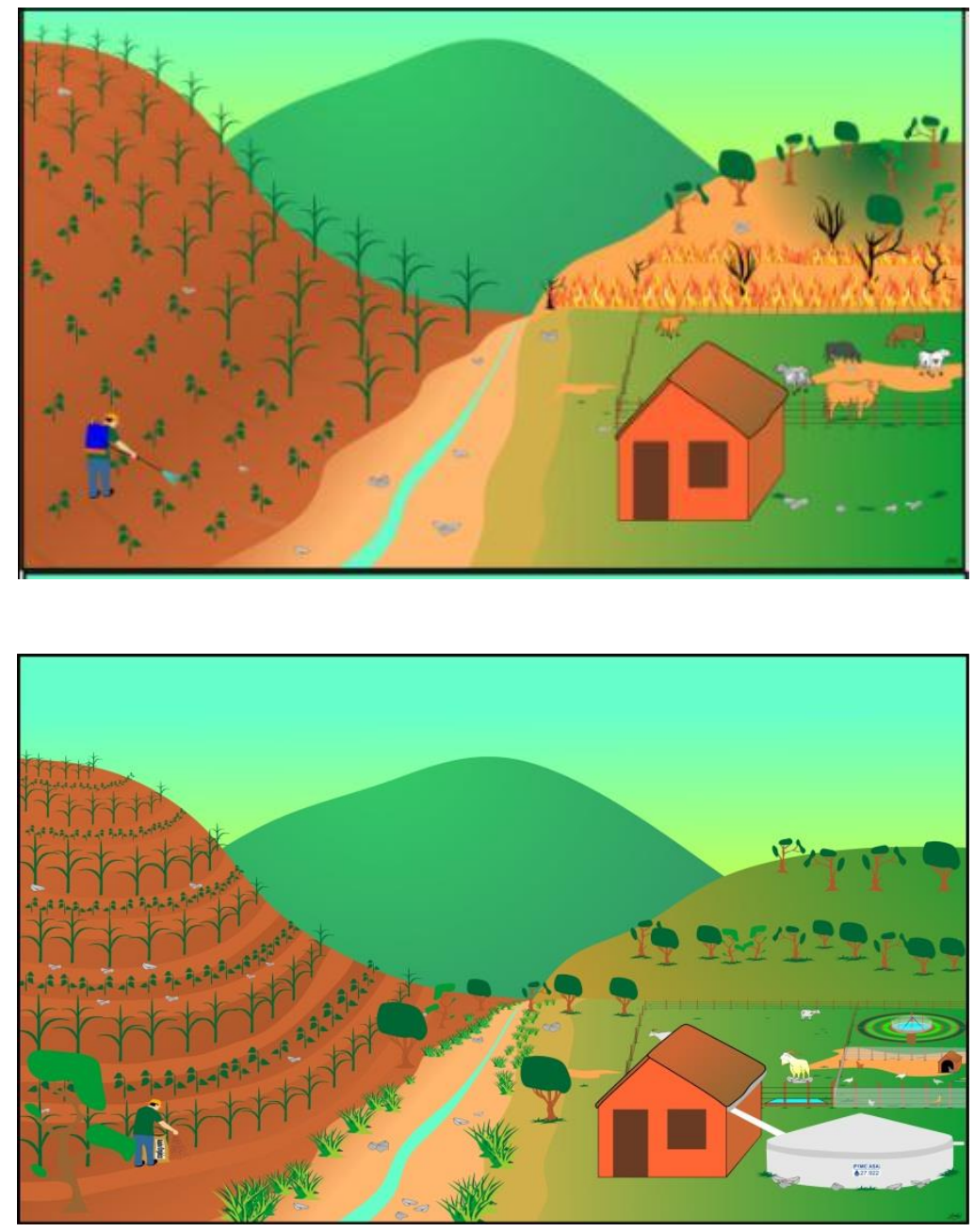

Arte gráfica: Mesquita 2016. 


\section{Fórum Ambiental

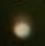

Figura 2. Quebra-cabeça da convivência com o semiárido
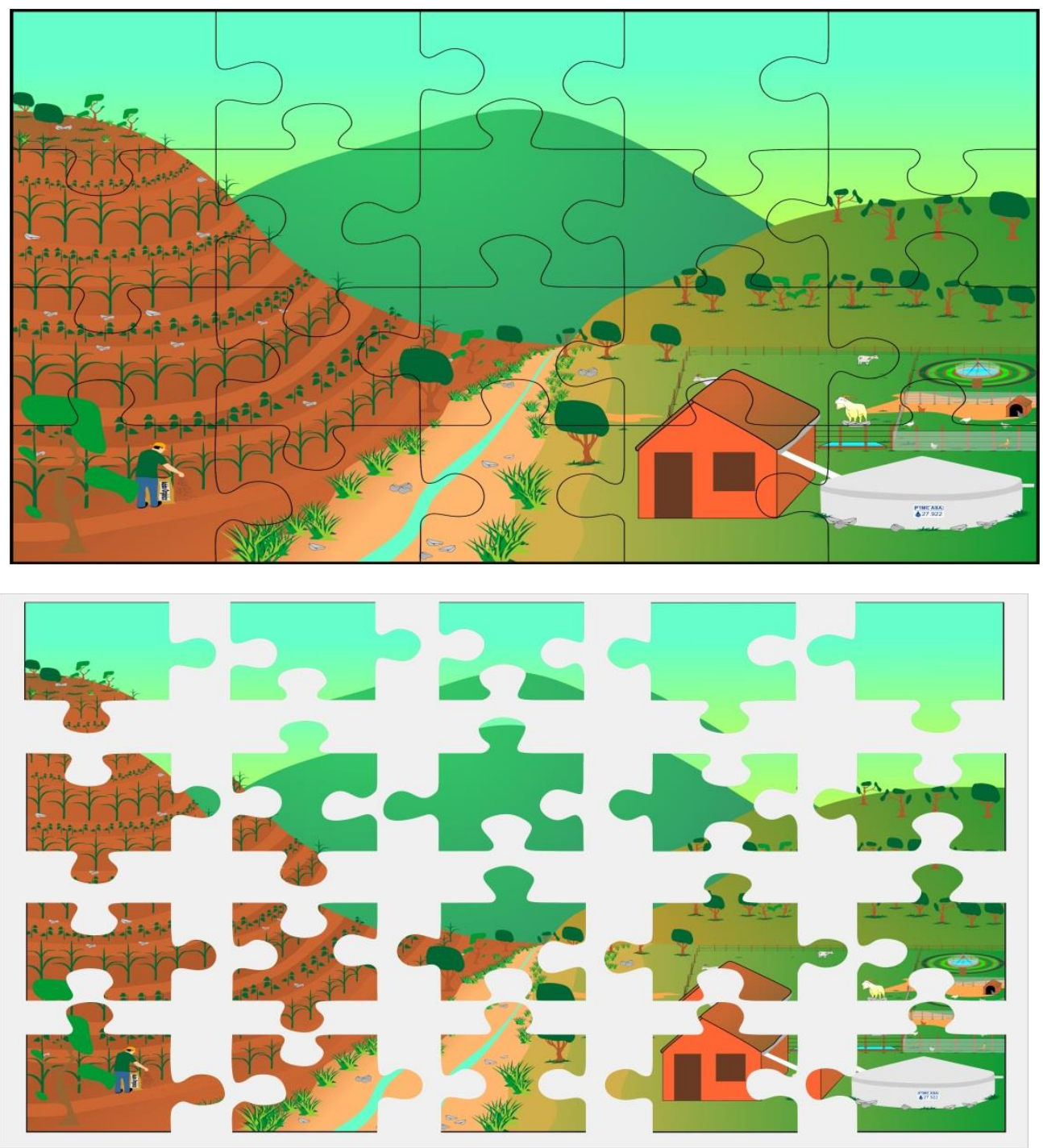

Arte gráfica: Mesquita (2016)

Especificando o propósito dos jogos, temos que evidenciar a forma a qual ocorreu a relação fator lúdico com assimilação de técnicas de convivência. Dessa forma, os Jogo dos Erros Quebra-cabeça foram concebidos dentro de um viés que promovesse, de maneira dialética, habilidades cognitivas e o saber sobre o semiárido.

É notório que jogos com o propósito de identificar erros e montagem de cenários existem inúmeros, no entanto, a grande maioria está atrelada a cenários e personagens de séries e desenhos da Disney, Marvel e outras produtoras. Estabelecemos então que, mais do que desenvolver a habilidade de montagem ou identificação de erros, propõe-se a introdução de saberes das práticas adequadas do manejo do nosso solo como nos mostram as figuras 1 e 2 . Há ainda a necessidade de justificar alguns pontos. Neste caso, como estamos trabalhando numa perspectiva do cotidiano do habitante da zona rural, quando abodarmos sobre a criação de animais de menor porte em detrimento de outros maiores, por exemplo, não se trata aqui 
de proibir a criação da segunda modalidade, mas privilegiando a primeira, o pequeno agricultor terá uma chance maior de êxito, pois necessitará de bem menos quantidade de água e alimentação, entretanto, com o devido acompanhamento técnico.

Nestas atividades os alunos terão que identificar erros e montar um cenário ideal para a convivência com o Semiárido, como já especificado. Em razão de se tratar do desenvolvimento de uma atividade a ser realizada a estudantes do ensino fundamental II, optamos, então, em conceituar "convivência com o Semiárido" sob a égide de fatores que estão mais próximos da realidade possível dos alunos e seus familiares.

Destacando sobre a contextualização, evidenciamos aos estudantes que a casa com cisterna supõe maior segurança hídrica; a preservação das matas, tanto nas encostas quanto no topo das serras são necessárias em função dos grandes processos de erosão que podem ser desencadeados, acontecendo o desmatamento das mesmas; a não prática de queimadas oferecerá um bom manejo dos solos, desde que seja explicado que haverá perca de nutrientes, juntamente com a proteção da mata ciliar do rio, que atrelada ao possível processo erosivo na serra poderia "entupir" o rio, como dito em uma das atividades dos erros da convivência.

\subsection{Parte operacional: apresentação de conteúdo e aplicação dos jogos: "Semiárido: conhecer para preservar"}

De início, é válido salientar que a oficina se realizou na escola Maria do Carmo Andrade, localizada em Sobral, no bairro Pedrinhas. Ao propormos as atividades à gestão da escola e o professor de Geografia, destacamos que para aplicação das atividades não nos impuseram nenhum problema, fomos prontamente aceitos, entretanto, que a mesma se constituísse em tempo limitado de $30 \mathrm{hs}$, pois os alunos estavam se preparando para avaliações internas e externas. No total, 20 alunos foram inseridos na proposta e, estes cursando o 6a ano.

No primeiro momento aplicamos um questionário com perguntas como: 1 . O que é Semiárido?; 2. Já visitou uma localidade do campo?; 3. Você já ouviu falar sobre Seca? e 4. Quais os problemas causados por ela?. Existe características do semiárido aqui no espaço da cidade? Nesse contexto, diante da realização dos questionários procurou-se saber como iriamos proceder durante o prosseguimento da atividade, pois tínhamos que traçar um perfil da turma, referente ao nível de conhecimento de cada aluno para o desenvolvimento mais equânime da oficina.

Após a aplicação do questionário, a atividade da oficina ocorreu em dois momentos, No primeiro, optamos por apresentar a caracterização da região semiárida, mostrando imagens dos tipos de vegetação, relevo, ecossistema, os solos, clima, fatores socioeconômicos e por último, adentrar ao problema da "Seca". 
Figura 3. Figura A, Abordagem teórica da oficina, no $1^{\circ}$ dia. Figura $\mathbf{B}$, Estudante respondendo ao jogo dos erros. Figuras C e D. Montagem do quebra-cabeça.
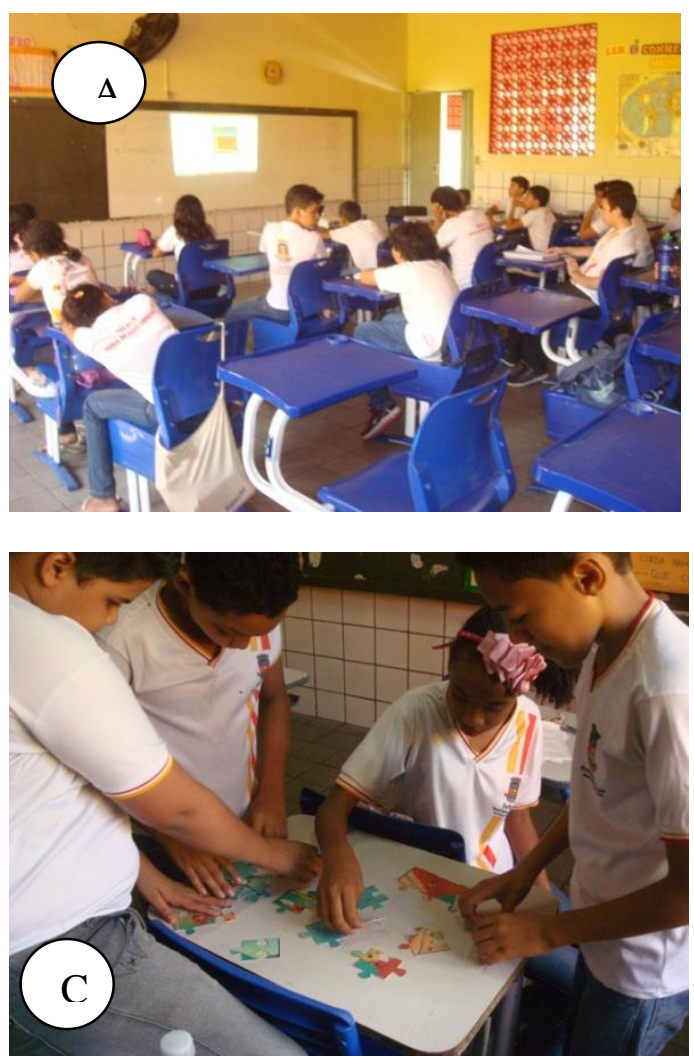
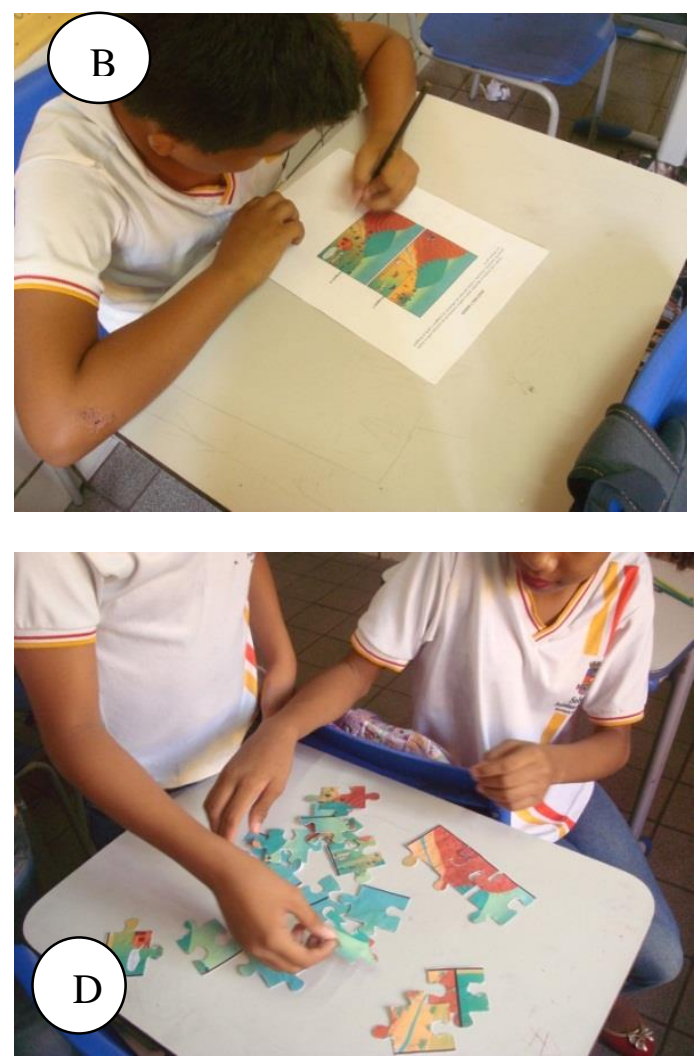

É notório que todos estes aspectos estão disponíveis na internet, por exemplo, entretanto, tratou-se a questão de analisá-los sob o ponto de vista que os alunos relacionassem os fatores de maneira sistêmica e crítica, da forma mais simples e viável.

Destacamos a aplicação de um questionário antes da atividade e pelo menos 6 estudantes tinham em comum que a região estudada faz alusão ao calor, pouca vegetação e água.

Para o prosseguimento da atividade, na segunda parte, a prática, aplicamos os jogos em caráter lúdico: Jogo dos erros da preservação do semiárido (ver figura 1) e quebra-cabeça da convivência com o semiárido (ver figura 2), com intuito de sabermos o nível de conhecimento do conteúdo exposto. 0 trabalho foi realizado em grupo (ver foto 3 a $, b, c, d$ )

E por fim, conversamos novamente com os alunos sobre os mesmos aspectos abordados no início da oficina e comprovamos a assimilação dos ensinamentos referentes à proteção das matas ciliares, plantações dispostas em curvas de nível, que de acordo com os próprios estudantes, a água fica "freada" e corre mais devagar. E a utilização de cisternas favorece a armazenagem de mais água.

\section{RESULTADOS E DISCUSSÕES}

Ao final da atividade e consequente aplicação dos jogos, pudemos averiguar que no primeiro dia de oficina, alguns alunos quando perguntamos sobre as características do nosso ambiente, apenas 1 , prontamente respondeu que se tratava de uma região muito quente e com pouca 
vegetação, é claro que os outros poderiam saber mais características, porém, não quiseram responder ou se talvez se sentiram tímidos para responder.

Além do mais, ressalta-se que, em nenhum momento das atividades, procuramos nos evidenciar como detentores de todo o saber e tecer críticas vazias ao professor de Geografia, tivemos alguns meses para o desenvolvimento exclusivo dos jogos, enquanto o professor dedica o seu estreito tempo para o ensinamento e aplicação de avaliações de Português e Matemática (conforme relatado pelo próprio professor de Geografia a quem nos reservamos o direito de não se identificar). Observamos também o grande distanciamento ainda há entre as problemáticas da sociedade e a praticidade das pesquisas acadêmicas.

Explicamos ainda sobre o comportamento da fauna e flora da região e quais fatos as levam a se adaptarem a nossa realidade. Salienta-se que os materiais funcionam como auxílio, desfazendo qualquer pensamento de desprezo ao trabalho do docente que está no cotidiano escolar e evidenciando o caráter de integração entre escola e universidade.

Sobre o aprendizado do conteúdo durante a oficina, salientamos que, em se tratando de conhecimento prévio dos alunos, apenas a ciência de que pertencemos a um ambiente quente, sem mais aprofundamentos. Referente a questionamentos após atividades, salientamos que todos fixaram a ideia de preservação das matas ciliares, resultado de uma ação que se promovera antes por nós de forma "extra oficina", digamos assim, através de estágios supervisionados.

Neste cenário, e diante do que propusemos: mostrar as possibilidades de convivência com o ambiente citado; introdução de ideias que colaborem com a desmistificação de algumas ações e utilização de novos recursos didáticos. Ao final, quando entregaram seus trabalhos, erros da convivência e quebra-cabeça, e a nossa consequente avaliação, conseguimos verificar que na maioria dos trabalhos, como já foi dito, os alunos puderam adquirir o entendimento com relação ao modo correto de se plantar uma lavoura (em curvas de nível) e a preservação das matas ciliares.

Referente às outras técnicas como: criação de animais menores; queimadas para novo plantio; uso de cisternas e mandalas e dentre outros. Acabaram por serem lembrados de forma secundária em razão de precisarem de um tempo maior de atividade.

Contudo, observou que após a aplicação das oficinas, toda a turma mostrou-se mais empenhada quando as perguntas foram novamente colocadas. As respostas saiam com fluidez e desembaraçamento pelos alunos. Muito provavelmente pelo descontrair dos mesmos, mas certamente pelo envolvimento na atividade e assimilação com a proposta do jogo.

\section{CONSIDERAÇÕES FINAIS}

A proposta de levar para a escola o conhecimento de uma realidade que, por vezes, se dissemina numa perspectiva que permeia a ausência ou pouca utilização de materiais de apoio didáticos que auxiliem no processo de aprendizagem, em detrimento da utilização somente do livro didático, tende a colaborar com à prática docente.

No caso, a introdução dos materiais trabalhados se fez importante para nós, pelo seu caráter inovador, logo o objetivo de ensinar sobre a preservação ambiental do Semiárido, apesar de praticamente partirmos de uma etapa quase inexistente, tornou-se revelador a curiosidade dos alunos frente a caracterização das limitações, diversidades e potencialidades da realidade do ambiente estudado. 
Assim sendo, consideramos o momento de todo o desenvolvimento da atividade, tanto teórica quanto a prática, de fundamental relevância no que pese a tomada de consciência de uma problemática com o auxílio de novos materiais de apoio didáticos.

\section{REFERÊNCIAS}

BRASIL. Ministério da Integração Nacional. Nova delimitação do Semiárido brasileiro.Brasília, DF, 2005. $32 \mathrm{p}$.

BRASIL, LDB. Lei 9394/96. Lei de Diretrizes e Bases da Educação Nacional. Disponível em <mec.gov.br/>. Acesso em: 04/08/2016.

BRASIL. Ministério da Educação e do Desporto. Secretaria de Educação Fundamental. Parâmetros curriculares nacionais terceiro e quarto ciclos do ensino fundamental: introdução aos parâmetros curriculares nacionais. Brasília, DF: MEC/SEF, 1997

BRASIL. Ministério da Educação e do Desporto. Secretaria de Educação Fundamental. Parâmetros curriculares nacionais História e Geografia. Brasília, DF: MEC/SEF, 1998

CAVALCANTI, L. S. Geografia, escola e construção de conhecimentos. Campinas - SP: Papirus, 2004.

CACETE, Núria Hanglei. Reforma educacional em questão: os parâmetros curriculares nacionais para o ensino de geografia e a formação de professores para a escola básica. In: ALBUQUERQUE, Maria Adailza Martins de; FERREIRA, Joseane Abílio de Sousa (Orgs.). Formação, pesquisa e práticas docentes: reformas curriculares em questão. João Pessoa: Mídia, 2013. p. 47-58.

COSTA FALCÃO, C.L. Programa Educação em Solos: conhecer, instrumentalizar e propagar. In: Extensionando: cultivando saber na escola e nas comunidades. FALCÃO SOBRINHO, J e LINS JR. J.R.F. Edições Universitárias. Sobral, 2014.

COSTA FALCÃO, C. L. A Dinâmica Erosiva do Escoamento Pluvial em Área de Depressão Sertaneja e de Maciço Residual no Semiárido cearense. 2008. 213 p. Tese (Doutorado em Geografia Física) - Faculdade de Letras Filosofia e Ciências Humanas, Universidade de São Paulo, São Paulo.

FALCÃO SOBRINHO, J. Relevo e Paisagem: proposta metodológica. Sobral: Sobral Gráfica. 2005. 108p. J; COSTA FALCÃO, C. L. Geografia Física: a natureza na pesquisa e no ensino. Rio de Janeiro. T.mais.oito. 2007. 86p.

GOULART, I. B. Piaget: Experiências básicas para utilização pelo professor. Petrópolis: Editora Vozes. 1983. p. 189.

GUIMARÃES, M. A dimensão ambiental na educação. Campinas: Papirus, 1995. 104p.

IBGE. Pesquisa Nacional por Amostra de Domicílios. 2010/2016. Disponível em: <http://cidades.ibge.gov.br/xtras/perfil.php?codmun=231290>. Acesso em: 21 de Ago. 2016.

PONTUSCHKA, N. N. A Geografia: ensino e pesquisa. In: CARLOS, A. F. (Org.).

Novos caminhos da Geografia. São Paulo: Contexto. 2001, p. 111-142.

QUINTELLA BAPTISTA, N. E CAMPOS, C. H. Educação contextualizada para a convivência com o Semiárido. In: CONTI, I. L. e SCHROEDER, E. O. Convivência com o Semiárido Brasileiro: autonomia e protagonismo social. Brasília: IABS. 2013, p. 83-96.

SILVA, R. M. A. Entre o combate à seca e a convivência com o semi-árido: transições paradigmáticas e sustentabilidade do desenvolvimento. 2006. 298 f. Tese (Doutorado em Desenvolvimento sustentável) - Universidade de Brasília, Brasília, DF, 2006. 
SOUZA, M. J. N de. Contexto Geoambiental do Semi-árido do Ceará: Problemas e Perspectivas.em: FALCÃO SOBRINHO, J. e COSTA FALCÃO, Cleire Lima (orgs.) Semi-árido: diversidades, fragilidades e potencialidades. Sobral Gráfica, 2006.

SUertegaraY, D. M. A. Pesquisa e Educação de Professores. In: PONTUSCHKA, Nídia N. e OLIVEIRA, Ariovaldo U. (orgs.). Geografia em Perspectiva: São Paulo: Contexto, 2004. p. 107-114. 